The International Journal of Multimedia \& Its Applications (IJMA) Vol.9, No.4/5/6, December 2017

\title{
The Relations Of MEtacognitive Awareness, MULTIPLE INTELLIGENCES, AND GENDER WITH Undergraduates' PerCeived Motivation IN USING MULTIMEDIA
}

\author{
Nurul Nadia Hassan, Khairulanuar Samsudin, Che Soh Said \\ Faculty of Art, Computing \& Creative Industry, Universiti Pendidikan Sultan Idris, \\ Tanjung Malim, Malaysia
}

\begin{abstract}
Learning Introductory Programming has always been challenging to computer science and information technology undergraduates and such problems, most notably comes from the lack of metacognitive awareness. Other important factors are multiple intelligences, gender, and motivation in using learning tools can also have a huge impact on learning the subject matter. A survey study was carried out with the aim to investigate the relationship among metacognitive awareness, gender and multiple intelligences towards perceived motivation of the students in learning using multimedia tools. 103 fresh undergraduates were recruited to participate in the survey. The data analysed using Pearson correlation and multiple linear regression analysis. The result showed that the correlation between metacognitive awareness and motivation in using multimedia tools was significant, positive, and moderately strong. These finding suggest that students with higher metacognitive awareness will be highly motivated in using multimedia tools compared to those with lower metacognitive awareness.
\end{abstract}

\section{KEYWORDS}

Introductory Programming, Gender, Metacognitive Awareness, Multiple Intelligences, Multimedia Tools

\section{INTRODUCTION}

Learning Introductory Programming has always been problematic, and it is becoming a major point of discussion among various fraternities in the academic world, particularly in the institutes of higher learning (IHLs). From the teaching standpoint, lecturers, teachers, and instructors agree that teaching Introductory Programming has always been challenging. Likewise, from the learning perspective, students believe that pursuing this course is more challenging compared to other courses. Being one of the core courses in Computer Science (CS) and Information Technology (IT) programs, first-year students of IHLs have to learn Introductory Programming in the early semester of the academic program. Thus, it is hardly surprising that many students have highlighted their difficulty in learning the subject matter to friends and instructors. Hence, many researchers have conducted several studies focusing on contributing factors in such difficulty, encompassing pedagogical, instructional, and psychological aspects. Unanimously, these researchers agreed that learning Introductory Programming entails students to possess adequate problem-solving skills and analytical thinking to understand and solve programming problems [14]. Lacking these skills at the early stage of learning could result in students getting poor grades after completing this course. These skills are not only important to pursuing students but also to programmers. Thus, aspiring to be programmers requires students to develop and enhance their problem-solving skills at the early stage of learning programming, which could help them deal with many challenging real-life problems [25]. 
Understanding on how to deal with the programming problems and the processes required to solve them has been discussed in the relevant literature. For example, Ismail and his colleagues identified that the important process in programming begins at the level of identifying and analysing a given problem [16]. To perform these two processes (i.e., identifying and analysing), students must have the appropriate skills or ability to help them solve a given problem. According to Breed, Mentz, and van der Westhuizen, learning programming entails students to have metacognitive awareness or metacognitive skills [4]. With appropriate level of metacognitive awareness, students will be able to plan, manage, monitor, and evaluate the process of solving a given problem effectively [4]. A number of studies have found that the lack of well-developed metacognitive skills or awareness is a major cause of learning problems in Introductory Programming [16][17]. Thus, lacking this ability will put students at risk, which ultimately leads to poor performance.

In addition to metacognitive awareness, several studies have shown that, in general, male students tend to perform relatively better than female students [3][25]. Thus, it is not surprising to see greater representation in CS and IT programs of the former compared to that of the latter. In fact, gender factor has been hotly debated - and it would continue to be debated - in many academic disciplines, most notably in science, technology, engineering, and mathematics (STEM), as societies become more egalitarian, transcending a wide range of socio-cultural dimensions. Nonetheless, many scholars contend that environmental or experiential factors rather than the biological factors are responsible for the higher representation of male students in STEM. As such, with proper training and learning, such gender disparity can be minimised or eliminated. In addition, students' innate abilities may also play an important role in learning or training. For example, students' multiple intelligences have been observed to exert a huge impact on learning achievements. According to Howard Gardner, a world-renown psychologist from Harvard, every human being has a diverse range of intelligences. In other words, individuals have multiple intelligences, not a single intelligence. Together, such intelligences play an important role in learning, as students with a particular dominant intelligence will learn or train better when exposed to a particular learning or training technique. Above all of the literature, this study conducted with the aim to investigate the relationship among metacognitive awareness, gender and multiple intelligences towards perceived motivation of the students in learning using multimedia tools.

\section{Enhancing Motivation Through Multimedia}

Clearly, motivation is one of the important factors to foster active, meaningful, and fun learning. Given its importance in learning, this construct has been widely researched for decades. The persistent interest is not surprising as motivation can be a decisive factor to the success, or to failure, in any academic pursuits. Many studies have shown that students' academic performances are highly related to their levels of motivation [6]. Especially in programming, motivation on student learning needs greater emphasis given that learning the subject matter is inherently challenging, which can easily make students unmotivated or frustrated [22].

To date, several experimental studies have been carried out to help improve students' motivation in learning. These studies employed a range of technologies to create interesting learning environments to help enhance student learning. Invariably, most of these studies employed multimedia learning tools to improve students' skills, knowledge, and motivation in various learning disciplines. Apparently, students became highly motivated in learning when they were given opportunity to use various learning features, such as feedback, interactivity, animations, audio narration, appealing graphics and videos. Such impacts on students' motivation are to be expected as research by Leow [6] showed that prompt feedback and interactive elements managed to make students highly engaged, cognitively aroused, and interested in partaking learning 
The International Journal of Multimedia \& Its Applications (IJMA) Vol.9, No.4/5/6, December 2017

activities. In addition, she observed that students became more persistent throughout the learning process.

\section{Metacognitive Awareness}

According to Schraw and Dennison [24], metacognitive knowledge can influence cognitive performance by enhancing the use of appropriate strategies. Likewise Schraw and Dennison's research findings showed that students who were metacognitively aware of the strategies that they used in learning could perform well compared to those who were unaware of it. In essence, metacognitive knowledge is associated with knowledge about cognition in general, which involves strategies that leaners use to improve learning process. Probably, strategies used in any decision making may not perfect to achieve the target goal, nevertheless they can enhance the process of learning. According to Pintrich [21], metacognitive knowledge can be categorized into three types, namely strategic knowledge, knowledge about cognitive tasks, and self-knowledge. Collectively, these types of knowledge are summoned through appropriate metacognitive process that helps improve strategies used in solving problems.

In this regard, metacognition is known as the ability of learners to take control of what they are learning and to understand their own ability to understand such learning. On the other hand, metacognitive skills are the ability of learners to use a precise strategy in a proper context, to monitoring their learning process, and, if required, to change such strategy with a new one [23][5]. Metacognitive skills are also known as 'knowing about knowing', suggesting that learners will be aware of the appropriate strategy that can help solve a problem. Metacognition enables learners to develop appropriate skills that help them in self-regulation, planning, and monitoring, which ultimately leads to improved self-directed learning [19].

A study by Caliskan and his colleague [5] found that using proper learning strategies could increase awareness of using such strategies, metacognitive knowledge, and metacognitive skills. Declarative, procedural, and conditional knowledge are subcomponents of metacognitive knowledge [23]. Interestingly, several studies have shown that improved metacognitive skills would have a strong impact on students' learning achievement. According to Flavell [8], who coined the term "metacognition", this constructy is a regulatory system that includes knowledge, goals, and strategies. Metacognitive knowledge is knowledge (or beliefs) about oneself, cognitive agents, tasks, actions, or strategies, and how all these interact with one another that can affect the outcome of any intellectual undertaking. Metacognitive experiences are conscious cognitive or affective experiences that concern any aspect of an intellectual undertaking.

According to Shraw and Dennison [24], metacognitive skills comprise two main components of cognition; knowledge of cognition $(\mathrm{KoC})$ and regulation of cognition $(\mathrm{RoC})$. Furthermore, $\mathrm{KoC}$ consists of three types of knowledge, namely declarative, procedural, and conditional knowledge. Declarative knowledge is knowledge about ones' skills, resource of intellectuality, and the ability to learn. Procedural knowledge is the knowledge of how to implement strategies or procedures. Conditional knowledge refer to the ability of an individual to know how and when to use proper strategies or procedures.

Regulation of cognition consists of five sub skills, namely planning, information management, monitoring, debugging, and evaluation. Planning skill comprises the ability of someone to plan, set goals, and allocate resources for learning. The second subskill is the ability to process information in a competent way (i.e., organizing, elaborating, summarizing, and selective focusing). Monitoring process involves the assessment of learning and strategy used by a learner. Debugging involves correcting or adjusting strategies used in the learning process that helps 
The International Journal of Multimedia \& Its Applications (IJMA) Vol.9, No.4/5/6, December 2017

minimize errors. Evaluation skill is the ability to analyse the performance and effectiveness of a strategy used in a particular learning activity.

\section{Impacts Of Gender, Multiple Intelligences, And Multimedia ON LEARNING}

Arguably, a host of factors, including biological and experimental factors such as gender, multiple intelligences, and multimedia, affect learning. As highlighted, multiple intelligences are individuals' abilities that are naturally developed, which can help them to carry out various undertakings. Essentially, intelligences are commonly related to individuals' concentration or interests. According to Gardner [11], everyone has eight (8) intelligences, namely verbal linguistic, logical mathematic, visual, body kinaesthetic, interpersonal, intrapersonal, musical and naturalist.

Verbal linguistic intelligence refers to the ability to use and manipulate verbal and written languages to achieve certain goals. Visual spatial intelligence is the ability to perceive and process visual information in the mind [12]. Logical mathematical is defined as the ability to analyse problems logically, solve mathematical problems, and investigate issues in a scientific way. Musical intelligence refers to the talent in composition, performance, and appreciation to music. Bodily kinaesthetic is the ability to use the whole or parts of body [10]. Intrapersonal as the ability to understand oneself that helps develop an effective working model of his or her own identity. Interpersonal intelligences is the ability to interact an to work with other people effectively. Naturalist intelligence refers to individuals' sensitivity toward nature, flora, and fauna and their ability to classify numerous species.

Research by Zarei and Azin found that visual and verbal intelligences were strong predictors of metacognition in self-regulated learning [27]. Theirs result also indicated that visual intelligence had negative relationship with metacognitive self-learning. Interestingly, they also found that use of multimedia could assist students to be more interested in learning, as graphic, videos, audios, and animations would be able to regulate other senses without relying on certain intelligences to support learning.

Multimedia learning can be engaging and meaningful that can help individuals to learn more effectively. Naturally, individuals have many different intelligences that can support them in the learning process. In this regard, understanding individual's multiple intelligences is important, because it helps identify their preferences for the type of learning that best suits their natural ability. Likewise, students need to be aware of their own learning ability or personal intelligences through metacognitive reflection and feedback in collaborative environment [15]. In other words, becoming aware of one's own intelligences is important to ensure he or she can learn to his or her maximum potential. In addition, research has also shown that multiple intelligences vary across gender. In particular, research by Menevis and Ozad [18] found out that there were significant differences between male and female in multiple intelligences, notably in verbal, kinaesthetic, existential, musical, interpersonal, intrapersonal, and naturalist intelligences. These findings suggest that female and male students have different As such, the use of multimedia can help both genders to learn more effectively as they can use specific multimedia elements that best match their dominants intelligences.

Research on modality effects such as texts and audio narration on multimedia learning have resulted in significant difference between male and female students [9]. The findings indicate that when the learning aim is to transfer information to a new context, male learners would have perform better than female learners, as the former are most adaptable to dual presentation mode 
The International Journal of Multimedia \& Its Applications (IJMA) Vol.9, No.4/5/6, December 2017

as opposed to the latter who tend to gain better from single mode presentation. Arguably, these findings suggest that female students are able to learn better using text without any other additional information. From the cognitive view, possibly male students would learn more effectively if information is delivered in more than one single mode. Based on the above discussion, the researchers formulated three research questions to address the prevailing issues as follows:

a) Does metacognitive awareness correlate with perceived motivation in learning using multimedia tools?

b) Does gender correlate with perceived motivation in learning using multimedia tools?

c) Do multiple intelligences correlate with perceived motivation in learning using multimedia tools?

Correspondingly, to answer the above research questions, the researchers hypothesized the followings:

a) Metacognitive awareness correlates significantly with perceived motivation in learning using multimedia tools.

b) Gender correlates significantly with perceived motivation in learning using multimedia tools.

c) Multiple intelligences correlate significantly with perceived motivation in learning using multimedia tools.

Based on the research hypotheses described above, the following represent the main objectives of this research:

a) To investigate the relationship between metacognitive awareness with perceived motivation in learning using multimedia tools.

b) To investigate the relationship between gender with perceived motivation in learning using multimedia tools.

c) To investigate the relationship between multiple intelligences with perceived motivation in learning using multimedia tools.

\section{RESEARCH METHOD}

Normally, a survey study is necessary to help the researcher to observe pattern of responses from a target focus [7]. In this research, a survey was carried out to examine engagement in learning using multimedia learning tool, comprising multimedia elements, such interactivity and feedback. This variable was analysed using an appropriate correlational statistical procedure by taking into account students' metacognitive skills awareness, multiple intelligences, and gender. In the survey, students' perception of learning the fundamental of programming were elicited. Nowadays, students prefer to use technology in their learning, and this interest invariably motivates them to learn in a learning environment that is supported by novel learning tools or applications. Thus, this factor served as the dependent variables of the survey research. The independent variables in this survey were students' metacognitive awareness and multiple intelligences; whereas, the moderating variable was students' gender. The relationships among these variables were analysed using appropriate correlational statistical procedures to reveal the significance, directions, and strengths of such relationships. 
The International Journal of Multimedia \& Its Applications (IJMA) Vol.9, No.4/5/6, December 2017

\subsection{Participants}

The participants involved in this survey were students from a local university in Perak, who were pursuing a degree study in Information Technology (IT). All of the participants already had learned the subject matter, and thus they were able to answer all the questions of the questionnaire. They were given ample time to go through and answer the questions. In addition, they were allowed to ask any questions if they had any doubts. In this survey, 103 students, consisting of 40 male and 63 female students, were recruited. Testing of the research hypotheses was based on the Alpha's confidence level at .05, to which decisions to accept or not to accept such hypotheses were referred. In addition, the strengths of the relationship between any two factors or variables were based on Piaw [20] recommendation, as shown in Table 1.

Table 1. Strengths of Relationships

\begin{tabular}{ll}
\hline Correlation Index & Interpretation \\
\hline $0.0-0.2$ & Very weak \\
\hline $0.21-0.4$ & Weak, Low \\
\hline $0.41-0.7$ & Medium \\
\hline $0.71-0.9$ & High, Strong \\
\hline $0.91-1.0$ & Very High, Very Strong \\
\hline
\end{tabular}

\subsection{RESEARCH INSTRUMENTS}

In this research, the instrument used was the survey questionnaire, which contained three (3) parts. Part A helped elicit information pertaining motivation in learning using multimedia tool, respectively. Part B helped obtain information regarding their multiple intelligences. Part $\mathrm{C}$ was based on the Metacognitive Awareness Inventory that was used to measure students' metacognition awareness. The measurements of the above constructs were based on 7-point Likert scales, ranging from "1" (Strongly disagree) to "7" (Strongly agree). On the other hand, for the measurement of multiple intelligences, the participants were required to indicate the appropriate intelligences that they thought as being either weak or strong, by marking the symbol " $\sqrt{ }$ " at the appropriate places. The validity and reliability of this part of the questionnaire was moderately high, which has been recorded to be .77 as reported in studies by [2]. The part of the questionnaire to elicit information related to motivation in learning using a learning tool (or application) was based on the modified instrument used in previous studies. For this research, several new items were added to the instrument to take into account of the motivational elements, such as interactivity, feedback and multimedia features. Overall, the reliability coefficients of Part A, Part B, and Part C of the research instrument were 0.89, 0.95, and 0.86, respectively, yielding an average reliability coefficient of .92 . Thus, the overall of the research instrument was deemed high, surpassing those recommended values 0.8 [1][7].

\subsection{Procedure}

This survey study will be conducted by giving a set of questionnaires to the students, which Motivation for Using Existing Learning Tool and Gardner Multiple Intelligences. The reliability values of the instruments for each part are as follows: (Part A) Motivation of learning using tools: 0.895; (Part B) MI: 0.862; (Part C) MAI: 0.956. The total average of the reliability values is 0.920. This shows that the reliabilities of these items are high because the values of the coefficients obtained are greater than the recommended value of 0.8 [1]. Moreover, Cohen and his colleagues state that alpha coefficient values ranging between 0.80 to 0.90 are high, indicating the high reliability of such a questionnaire [7]. 
The International Journal of Multimedia \& Its Applications (IJMA) Vol.9, No.4/5/6, December 2017

\section{RESULTS}

All data collected were analysed using the Statistical Package for Social Science (SPSS) to reveal both descriptive and inferential statistics. Table 2 summarizes the results of the respondents' perceived motivation in learning Introductory Programming using multimedia tools, awareness of metacognitive, and multiple intelligences. The mean scores of verbal linguistic intelligence of female and male respondents were 4.90 (1.89) and 4.43 (2.14), respectively. For logical mathematic intelligence, the female and male respondents attained the mean scores of 6.56 (1.55) and 5.90 (1.79). The mean scores of visual intelligence of female and male respondents were 6.52 (2.13) and 6.70 (2.07), respectively. For kinaesthetic intelligence, the female and male respondents attained the mean scores of 6.75 (2.33) and 6.80 (1.90). The mean scores of musical intelligence of female and male respondents were 4.89 (2.20) and 4.83 (1.63), respectively. For interpersonal intelligence, the female and male respondents attained the mean scores of 6.37 (1.96) and 6.60 (2.11). The mean scores of intrapersonal intelligence of female and male respondents were 7.56 (1.95) and 7.38 (1.97), respectively. For naturalist intelligence, the female and male respondents attained the mean scores of $5.46(2.48)$ and 5.75 (2.06).

Table 2. Mean values and standard deviations of motivation, intelligences and metacognitive awareness

\begin{tabular}{|c|c|c|c|c|}
\hline & & \multicolumn{3}{|l|}{ Means (SD) } \\
\hline & & $\begin{array}{l}\text { Females } \\
(n=63)\end{array}$ & $\begin{array}{l}\text { Males } \\
(n=40)\end{array}$ & $\begin{array}{l}\text { All } \\
(N=103)\end{array}$ \\
\hline \multirow{4}{*}{ Motivation } & Interactivity & $6.05(.64)$ & $6.10(.66)$ & $6.07(.65)$ \\
\hline & Feedback & $6.04(.69)$ & $6.10(.58)$ & $6.06(.65)$ \\
\hline & Multimedia & $6.01(.69)$ & $6.10(.61)$ & $6.06(.58)$ \\
\hline & Motivation & $6.06(.58)$ & $6.10(.55)$ & $6.05(.58)$ \\
\hline \multirow{11}{*}{ MA } & $\begin{array}{l}\text { Knowledge of Cognition } \\
(\text { KoC) }\end{array}$ & $5.25(.62)$ & $5.25(.70)$ & $5.25(.65)$ \\
\hline & $\begin{array}{l}\text { Regulation of Cognition } \\
\text { (RoC) }\end{array}$ & $5.52(.55)$ & $5.34(.74)$ & $5.43(.63)$ \\
\hline & MA & $5.42(.55)$ & $5.31(.71)$ & $5.38(.62)$ \\
\hline & Verbal Linguistic & $4.43(2.14)$ & $4.90(1.89)$ & $4.67(1.99)$ \\
\hline & Logical Mathematic & $5.90(1.79)$ & $6.56(1.55)$ & $6.23(1.67)$ \\
\hline & Visual & $6.70(2.07)$ & $6.52(2.13)$ & $6.61(2.10)$ \\
\hline & Kinaesthetic & $6.80(1.90)$ & $6.75(2.33)$ & $6.77(2.16)$ \\
\hline & Musical & $4.83(1.63)$ & $4.89(2.20)$ & $4.86(1.99)$ \\
\hline & Interpersonal & $6.60(2.11)$ & $6.37(1.96)$ & $6.45(2.01)$ \\
\hline & Intrapersonal & $7.38(1.97)$ & $7.56(1.95)$ & $7.47(1.95)$ \\
\hline & Naturalist & $5.75(2.06)$ & $5.46(2.48)$ & $5.61(2.32)$ \\
\hline
\end{tabular}

The results showed that the metacognitive awareness of female students was higher than male students only for one sub-process, namely RoC, where the former attained a mean score of 5.52, as opposed to the latter who attained a mean score of to 5.34. Interestingly, both genders attained similar mean score of 5.25 for knowledge of cognitive awareness. As for their perception on the use of learning multimedia tool with high interactivity and feedback, male students had higher tendency than that of female students in using such a tool in learning. Even though both genders indicated strong interest in using multimedia learning tool, male students were more enthusiastic than the female counterparts were.

\subsection{Relationship among metacognitive awareness, gender, multiple intelligences towards perceived motivation}


Findings displays that there are weak relationship and no significant result between gender and perceived motivation. The result point to the tendency of male students to have more tendency having multimedia tools into the learning environment. Descriptive result of mean value support the indication that male students have slightly high mean value compared to female students. Result from the survey towards their motivation on learning using multimedia based tool, generally male students show the tendency to be more interested in using multimedia based tool in learning environment. The correlation value shows low and no significant relationship, but the mean score in the descriptive result does support this result.

The relationship between metacognitive skills and motivation towards learning with multimedia tool in Table 3 displays highly significant and low and medium strength of relationship. Giving feedback during learning process will help students have a better learning environment for both processes (knowledge and regulation of cognition) as the results expressing medium strength of relationship and highly significant; $r(103)=.432 p=0.00$ and $r(103)=.408 p=0.00$. For multimedia used during learning, process in KoC shows slightly high $r(103)=.387 p=0.00$ compared to $r(103)=.318 p=0.01$ for subprocess of cognition regulation. Both indicate weak strength of relationship and very strong significant. For KoC subprocess, the correlation with interactivity is significant and weak relationship $r(103)=.265 p=0.07$ and $r(103)=.259 p=$ 0.08 for regulation of cognition. This indicates that interactivity elements in a learning tool will better increase the process of knowing the ability of a learner to use resources based on their prior knowledge, but not the ability of a learner to organize and plan for more effective ways to increase skills in learning. As for gender, relationship are weak and no significant found for interactivity $r(103)=-.029 p=0.773$, feedback $r(103)=-.048 p=0.28$ and multimedia $r(103)$ $=-.067 p=0.503$. This indicates that male and female students has no different trend of learning, both genders agree to use multimedia based tool in their learning environment.

Table 3. Pearson correlation for metacognitive awareness, gender towards the motivation using multimedia tool in learning

\begin{tabular}{llll}
\hline & Interactivity & Feedback & Multimedia \\
\hline KoC & $.265 * *$ & $.432 * *$ & $.387 * *$ \\
\hline RoC & $.259 *$ & $.408 * *$ & $.318 * *$ \\
\hline Gender & -.029 & -.048 & -.067 \\
\hline \multirow{2}{*}{ Correlation is significant at the 0.01 level (2-tailed) } \\
*Correlation is significant at the 0.05 level (2-tailed)
\end{tabular}

According to the result shown in Table 4, there are no negative relationship, but significant and weak correlation in logical mathematic and intrapersonal intelligences. The correlation between logical mathematic and feedback show a stronger relationship than interactivity and multimedia elements. Giving response while learning shows low and significant $r(103)=.264, p=0.07$ for logical matematic compared to interactivity and multimedia elements; $r(103)=.246, p=0.12$ and $r(103)=.226, p=0.22$.

Visual learners show significant and weak relationships towards feedback and multimedia are $(103)=.23, p=0.16$ and $r(103)=.226, p=0.022$. No significant and weaker relationship was found against visual intelligent students and interactivity activity $r(103)=.157, p=0.112$. Interpersonal learners present low relationship and significant results towards interactivity $r(103)$ $=.229, p=0.20$, feedback $r(103)=.268, p=0.006$ and multimedia elements $r(103)=.289, p=$ 0.003 . This outcome indicates that interpersonal learners rather learning using multimedia based on tool to be blended in learning environment. 
The International Journal of Multimedia \& Its Applications (IJMA) Vol.9, No.4/5/6, December 2017

Table 4. Pearson correlation for intelligences towards the motivation using multimedia tool in learning

\begin{tabular}{llll}
\hline & Interactivity & Feedback & Multimedia \\
\hline Verbal Linguistic & .036 & .158 & .130 \\
\hline Logical Mathematic & $.246^{*}$ & $.264^{* *}$ & $.238^{*}$ \\
\hline Visual & .157 & $.237^{*}$ & $.226^{*}$ \\
\hline Kinaesthetic & .161 & .135 & .159 \\
\hline Musical & .062 & .035 & .059 \\
\hline Interpersonal & $.229 *$ & $.268^{* *}$ & $.289^{* *}$ \\
\hline Intrapersonal & .145 & .131 & .098 \\
\hline Naturalist & .174 & .126 & .132 \\
\hline $\begin{array}{l}* \text { Correlation is significant at the } 0.01 \text { level (2-tailed) } \\
* \text { Correlation is significant at the } 0.05 \text { level (2-tailed) }\end{array}$
\end{tabular}

Interrelations among all the variables were also analysed, yielding a mix of results. For example, a high significant positive relation between $\mathrm{KoC}$ and $\mathrm{RoC}, r(103)=.85, p<.001$ was found. A medium significant positive relation was found between visual and kinestatic intelligences, $r(103)$ $=.55, p<.001$. Likewise, a medium significant positive relation was found between visual and musical intelligences, $r(103)=.55, p<.001$. For logical mathematical and visual intelligences, their relation was found to be significantly positive and moderately strong, $r(103)=.47, p<.001$. Similarly, logical mathematical and verbal intelligences, their relation was also found to be significantly positive and moderately strong, $r(103)=.53, p<.001$. Table 5 summarizes the remaining intercorrelations among all the variables studied.

Table 5. Interrelations among all variables

\begin{tabular}{|c|c|c|c|c|c|c|c|c|c|c|c|}
\hline & 2 & 3 & 4 & 5 & 6 & 7 & 8 & 9 & 10 & 11 & 12 \\
\hline 1.Gender & -.056 & -.001 & -.0 .56 & .118 & .192 & -.041 & -.012 & .016 & -.057 & .045 & -.061 \\
\hline 2.Motivation & 1 & $.404^{* * *}$ & $.368^{* * *}$ & .115 & $.278^{* * *}$ & $.229^{*}$ & .167 & .051 & $.291^{* *}$ & .137 & .157 \\
\hline 3.KoC & & 1 & $.853^{* * *}$ & $.299^{* * *}$ & $.289^{* * *}$ & $.238^{*}$ & $.238^{*}$ & .167 & .171 & $.279^{* * *}$ & $.234^{*}$ \\
\hline 4.RoC & & & 1 & $.232^{* * *}$ & $.234^{* * *}$ & .168 & .168 & .131 & .139 & $.260^{* * *}$ & $219^{*}$ \\
\hline 5.Verbal & & & & 1 & $.528^{* * *}$ & $.456^{* * *}$ & $.506^{* *}$ & $.472^{* * *}$ & $.509^{* * *}$ & $.381^{* * *}$ & $.453^{* * *}$ \\
\hline 6.Math Logical & & & & & 1 & $.465^{* * *}$ & $.380^{* * *}$ & $.354^{* * *}$ & $.398^{* * *}$ & $.378^{* * *}$ & $.334^{* * *}$ \\
\hline 7.Visual & & & & & & 1 & $.552^{* * *}$ & $.552^{* * *}$ & $.432^{* * *}$ & $.329^{* * *}$ & $.526^{* * *}$ \\
\hline 8.Kinestatic & & & & & & & 1 & $.503^{* * *}$ & $.457^{* * *}$ & $.388^{* * *}$ & .549 \\
\hline 9.Musical & & & & & & & & 1 & $.407^{* * *}$ & $.338^{* * *}$ & $.384^{* * *}$ \\
\hline 10.Interpersonal & & & & & & & & & 1 & $.333^{* * *}$ & $.422^{* * *}$ \\
\hline 11.Intrapersonal & & & & & & & & & & 1 & $.493^{* * *}$ \\
\hline 12.Naturalist & & & & & & & & & & & 1 \\
\hline
\end{tabular}

\subsection{Interpersonal intelligences affect on student's motivation in using multimedia tools}

The multiple linear regression analysis performed showed that motivation in using multimediabased tool was significantly correlated with interpersonal intelligence, attaining a correlation coefficient of 0.53 (at $\mathrm{p}<0.05$ significant level). With $\mathrm{R}^{2}=0.281$, the results indicated that $28.1 \%$ of the variance in motivation (criterion variable) was accounted for by interpersonal intelligence (predictor variable). As such, $71.9 \%$ of the variance in motivation. Almost $30 \%$ the variance in 
The International Journal of Multimedia \& Its Applications (IJMA) Vol.9, No.4/5/6, December 2017

motivation elements or features such as interactivity and feedback was accounted for by such intelligence. Despite the poor fit of the regression model, with $R^{2}=28.1 \%$, the overall relationship was significant, $F(11,91)=3.24, p<.01)$, as summarized in Table 6 . As such, these elements can be utilised to create an interactive and appealing learning environment in which students can learn with higher engagement, commitment, and persistency [6].

Table 6. ANOVA for multiple intelligences, gender, and metacognitive awareness

On perceived motivation in using multimedia tools

\begin{tabular}{llllllll}
\hline Source of Variation & \multirow{2}{*}{ Sum of Squares } & $d f$ & Mean Square & $F$ & $R$ & $R^{2}$ & Sig \\
\hline Regression & 9.713 & 11 & .883 & 3.241 & .531 & .281 & .001 \\
\hline Residual & 24.795 & 91 & .272 & & & & \\
\hline Total & 24.509 & 102 & & & & & \\
\hline
\end{tabular}

As indicated in Table 7, there was no significant respondents' perceived motivation in learning with multimedia.

Table 7. Regression analysis coefficient for perceived motivation on multimedia tools

\begin{tabular}{llllll}
\hline & \multicolumn{2}{l}{$\begin{array}{l}\text { Unstandardized } \\
\text { Coefficients }\end{array}$} & $\begin{array}{l}\text { Standardised } \\
\text { Coefficients }\end{array}$ & $t$ & $p$-value \\
\cline { 2 - 7 } & $\beta$ & Std. Error & & & \\
\hline Constant & 3.708 & .502 & & .7 .381 & .000 \\
\hline Gender & -.074 & .116 &.- .062 & -.638 & .525 \\
\hline KoC & .247 & .167 & .275 & 1.478 & .143 \\
\hline RoC & -.107 & .167 & .117 & .642 & .523 \\
\hline Verbal Linguistic & -.059 & .036 &.-201 & -.1 .612 & .110 \\
\hline Logical Mathematic &. .066 & .040 & .190 & 1.642 & .104 \\
\hline Visual & .031 & .035 & .112 & .882 & .380 \\
\hline Kinaesthetic & .019 & .034 & .071 & .568 & .572 \\
\hline Musical & -.046 & .034 & -.157 & -1.360 & .177 \\
\hline Interpersonal & .076 & .032 & .264 & 2.363 & .020 \\
\hline Intrapersonal & -.013 & .032 & -.044 & -.404 & .687 \\
\hline Naturalist & -.009 & .030 & -.039 & -1.478 & .768 \\
\hline
\end{tabular}

\section{DISCUSSION AND CONCLUSION}

The survey conducted provided several important findings, particularly regarding the respondents' acceptance of the use of multimedia-based tool in learning. The results showed that levels of students' multiple intelligences varied across gender, with female students having four dominant intelligences, namely verbal linguistic, logical mathematic, musical, and intrapersonal. In contrast, male students tended to have other four intelligences, namely visual, kinaesthetic, interpersonal, and naturalist. Such findings are consistent with the findings of research by Menevis and Ozad [18], who found significant differences between male and female in verbal, kinaesthetic, existential, musical, interpersonal, intrapersonal, and naturalist intelligences. As such, these findings will have profound impacts on student learning based on the learning environment to which students are exposed. In this regard, multimedia technology can be a potent technology to help students of diverse multiples intelligence to learn effectively and efficiently. 
Correlational analysis performed yielded several interesting results. For example, logical mathematic and interpersonal intelligences, among other multiple intelligences, were significantly correlated with interactivity, feedback, and multimedia elements, but their correlations were small. Particularly, visual learners had a significant but weak relationship with feedback and multimedia features of the learning. In addition, students with strong visual, mathematical logic, and interpersonal intelligences were observed to be highly excited in using multimedia-based learning tool in learning process. On the other hand, respondents with dominant verbal linguistic, kinestatic, musical, intrapersonal, and naturalist intelligences did not any strong preferences such multimedia elements of the learnig tool.

Significant but weak relationships were found among logical mathematics, visual and interpersonal learners with motivation in learning using multimedia tool, suggesting that students with such abilities would be able to learn effectively with the presence of high interactivity and feedback in the learning process. Additionally, the relationships between verbal linguistic and visual intelligences with perceived difficulty in learning introductory programming were found to be significant, but low in magnitude. This particular finding is hardly surprising given that this course has many abstract and complex topics, of which students need to have strong or welldeveloped visualization skill to solve such topics by visualizing the problem-solving process. Arguably, students lacking this skill or verbal linguistic learners may need to rely on appropriate multimedia elements to help them visualize such a process in dealing with programming problems.

Correlational analyses performed on all variables showed significant interrelations, with magnitudes ranging from weak to moderate. In fact, the highest interrelations were observed among visual, kinestatic, and musical intelligences. In contrast, the interrelation between visual and interpersonal intelligence was observed to be the weakest. Again, such findings are consistent with the findings of Furnham's study, who found students with strong kinaesthetic intelligence tended to use parts or whole body to resolve problems [10]. Moreover, it is not surprising to notice that kinaesthetic learners were also dominant musical learners, as both intelligences are closely linked. Interpersonal learners, on the other hand, would prefer to have closer interaction with others in dealing with a host of problems or issues. Furthermore, visual learners would be naturally inclined to use images, graphics, or animations to help them in learning programming, as these multimedia elements can help them manipulate learning objects with ease. As such, the above preferences may partly explain the weak correlation between visual and interpersonal intelligences.

Similar analyses also showed the correlation between metacognitive awareness and feedback feature was significant and moderately strong. However, the correlations between metacognitive awareness and multimedia and interactive elements were also significant, but low in strength. As such, respondents with high awareness of both sub-processes would prefer to use such a multimedia-based learning tool. This finding suggest that students with such an awareness would be able to monitor their learning in self-learning mode more effectively, in which they may not be too dependent on using such a learning tool.

Strong and significant relations among metacognitive sub-skills ( $\mathrm{KoC}$ and $\mathrm{RoC})$ were observed, indicating that those who had better knowledge in choosing strategies to be applied in problemsolving context had higher ability to analyse and carry out self-assessment that helped in learning. Additionally, it was not surprising to find out relations among metacognitive skills, verbal linguistic, logical mathematics, intrapersonal, and naturalist intelligences were weak. Such findings reinforce the contention that individuals with strong intrapersonal understanding are likely to have high self-motivation and self-efficacy [15][13], thus leading to improved metacognition. Moreover, logical mathematics intelligence reflects individuals' ability to think 
The International Journal of Multimedia \& Its Applications (IJMA) Vol.9, No.4/5/6, December 2017

logically of concepts of logical arrangement of strategies, thus gaining better metacognitive awareness.

Overall, the findings of this study suggest that students have a diverse range of intelligences, with some being more dominants than others for both genders. In general, male students tend to have strong visual and kinaesthetic intelligences; whereas, female students tend to have strong verbal interpersonal intelligences. The findings also indicate that students with high metacognition tend to have higher motivation in learning. Additionally, some intelligences such as visual and logicalmathematical intelligences correlate significantly with motivation in learning. Taken together, these findings will have profound impacts on student learning. In this regard, multimedia technology can be used to help improve student learning by providing various multimedia elements or features by which students can capitalise on specific multimedia elements to help them learn abstract and complex programming concepts.

\section{REFERENCES}

[1] Abd Ghaffar, Mohd Najib (2003). Reka Bentuk Tinjauan Soal Selidik Pendidikan. Penerbit Universiti Teknologi Malaysia.

[2] Azid @ Aziz, N. Wahida (2005). Hubungan pola kepelbagaian kecerdasan pelbagai Gardner dengan aktiviti Schoolwide Enrichment Model (SEM) di kalangan pelajar Maktab Rendah Sains Mara. UTM. Master Thesis.

[3] Baser, M. (2013). Attitude, Gender and Achievement in Computer Programming. Online Submission, ERIC, EBSCOhost

[4] Breed, B., Mentz, E., \& van der Westhuizen, G. (2014). A Metacognitive Approach to Pair Programming: Influence on Metacognitive Awareness. Electronic Journal Of Research In Educational Psychology, 12(1), 33-59. doi:10.14204/ejrep.32.13104

[5] Caliskan, M., \& Sunbul, A. (2011). The Effects of Learning Strategies Instruction on Metacognitive Knowledge, Using Metacognitive Skills and Academic Achievement (Primary Education Sixth Grade Turkish Course Sample). Educational Sciences: Theory And Practice, 11(1), 148-153

[6] Leow, F., \& Neo, M. (2014). Interactive Multimedia Learning: Innovating Classroom Education in a Malaysian University. Turkish Online Journal Of Educational Technology - TOJET, 13(2), 99-110.

[7] Cohen.L et.al (2007). Research Methods in Education (6th Edition). Routledge Taylor \& Francis Group. Taylor \& Francis e-Library

[8] Flavell, J. (1979). Metacognition and cognitive monitoring: A new era of cognitive-developmental inquiry. American Psychologist, 34,906-911

[9] Flores, R., Coward, F., \& Crooks, S. M. (2011). Examining the Influence of Gender on the Modality Effect. Journal Of Educational Technology Systems, 39(1), 87-103

[10] Furnham, A. (2009). The Validity of a New, Self-report Measure of Multiple Intelligence. Current Psychology, 28(4), 225-239. doi:10.1007/s12144-009-9064-z

[11] Gardner, Howard (1993), Multiple Intelligences: The Theory in Practice. New York, USA: BasicBooks

[12] Joneja, R. (2016). Study of Multiple Intelligences Model of Howard Gardner in Higher Education. Aweshkar Research Journal, 21(2), 13-18. Education Research Complete, EBSCOhost 
The International Journal of Multimedia \& Its Applications (IJMA) Vol.9, No.4/5/6, December 2017

[13] Andronache, D., Bocoş, M., Stanciu, D. I., \& Raluca, B. O. (2011). The valences of multiple intelligences theory in optimizing the training process. Journal Of Educational Sciences / Revista De Stiintele Educatiei, 13(2), 18-26

[14] Hui, T., \& Umar, I. N. (2011). Does a Combination of Metaphor and Pairing Activity Help Programming Performance of Students with Different Self-Regulated Learning Level?Turkish Online Journal Of Educational Technology - TOJET, 10(4), 121-129

[15] Hyerle, D. (2011). Student successes with Thinking Maps, Second edition. Thousand Oaks: Corwin Press

[16] Cetin, I., Sendurur, E., \& Sendurur, P. (2014). Assessing the Impact of Meta-Cognitive Training on Students' Understanding of Introductory Programming Concepts. Journal Of Educational Computing Research, 50(4), 507-524.

[17] Ismail, M. N., Ngah, N. A., \& Umar, I. N. (2010) .The effects of mind mapping with cooperative learning on programming performance, problem solving skill and metacognitive knowledge among computer science students. Journal of. Educational Computing Research, Vol. 42(1), pp. 35-61.

[18] Menevis, I., \& Ozad, B. (2014). Do Age And Gender Influence Multiple Intelligences?. Social Behavior \& Personality: An International Journal, 429-19. doi:10.2224/sbp.2014.42.0.S9

[19] Pang, K. (2010). Creating Stimulating Learning And Thinking Using New Models Of Activity-Based Learning And Metacognitive-Based Activities. Journal of College Teaching \& Learning, 7(4), 29-38

[20] Piaw, Chua Yan (2013). Mastering Research Statistics. McGraw-Hill Education (Malaysia) Sdn. Bhd.Selangor, Malaysia.

[21] Pintrich, P. R. (2002). The Role of Metacognitive Knowledge in Learning, Teaching, and Assessing. Theory Into Practice, 41(4), 220

[22] Ibrahim, Roslina (2011). Perceptions on using educational games to learn introductory programming. Computer and information science. Vol. 4, No. 1

[23] Schraw, G. and Moshman, D. (1995). Metacognitive Theories. Educational Psychology Review, 7(4), 351-371.

[24] Schraw, G. and Dennison R. S. (1994).Assessing metacognitive awareness. Contemporary Educational Psychology, vol. 19, pp. 460-475.

[25] Sullivan, A., \& Bers, M. (2013). Gender differences in kindergarteners' robotics and programming achievement. International Journal Of Technology \& Design Education, 23(3), 691-702. doi:10.1007/s10798-012-9210-z

[26] Tseng S. and Weng J. (2010). Finding trustworthy experts to help problem solving on the programming learning forum," Interactive Learning Environments, vol. 18(1), pp.81-99

[27] Zarei A. A., \& Azin Z. (2013). Multiple Intelligences as predictors Cognitive and Metacognitive Selfregulated Learning. International Journal of Management and Humanity Sciences. Vol., 2 (S), 844 853

\section{Authors}

Dr. Khairulanuar Samsudin holds a bachelor's degree in Mechanical Engineering, a Master's degree in advanced manufacturing technology, and a doctoral degree specialising in virtual reality for spatial visualization. He used to work as a mechanical engineer at Motorola Communication, Penang and as a lecturer at Ipoh and Jitra polytechnics. Later, he joined Sultan Idris University of Education, Tanjung Malim, Perak where he teaches Computer Aided Design, Product Data Management, and Research Method. To date, he has conducted several research focuses on the

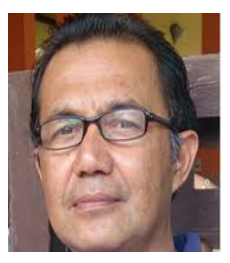


The International Journal of Multimedia \& Its Applications (IJMA) Vol.9, No.4/5/6, December 2017

application of virtual reality and mobile augmented reality on learning and training and published several academic papers.

Che Soh Said is a senior lecturer of Information Technology in Department of Computing in Faculty of Art, Computing and Creative Industry, University Pendidikan Sultan Idris. He earned his Bachelor of Science in Computer and Education at the University Technology of Malaysia, Master Degree in Computer Science at the University Putra of Malaysia and his PhD from University Sains of Malaysia. His research and teaching interests include virtual reality, augmented reality, computer animation and instructional technology. Che Soh have been teaching multimedia software design, computer animation, educational research method, mathematics for computer science, philosophy of knowledge and

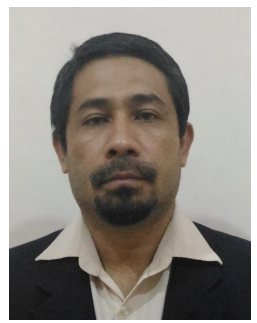
integration computing and educational throughout his twenty years of academics journey. He has published numbers of article in academics journal such as Educational Society and Technology Journal, Journal of Science, Mathematics and Technology, Journal of ICT in Education, and Malaysian Journal of Science and Mathematics Education.

Nurul Nadia Hassan acquired her bachelor's degree in Computer Science (software engineering) and Master's degree in Educational Technology from Universiti Teknologi Malaysia (UTM). Currently pursuing her study in Doctor if Philosophy in Multimedia Education at Universiti Pendidikan Sultan Idris (UPSI). She used to work as an Information Technology lecturer for few years before continuing her study. Now, she is actively doing research self regulated learning, metacognitive skills and multimedia in education.

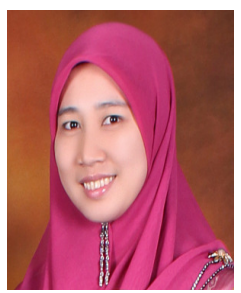

